Global Women's Breakfast 2022

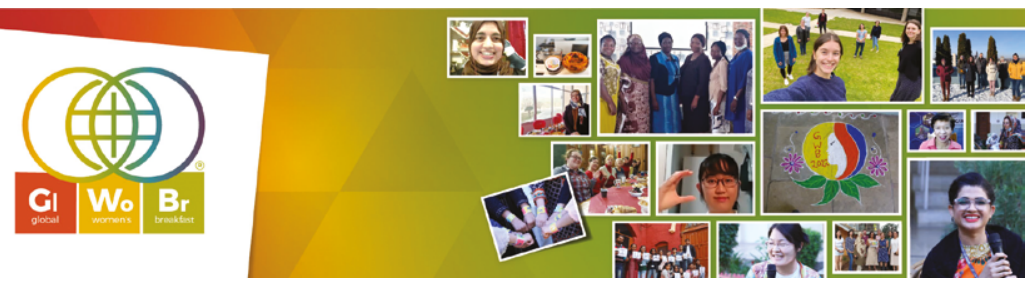

O Global Women's Breakfast 2022 realizar-se-á no dia 16 de fevereiro, logo após o Dia Internacional de Mulheres e Raparigas na Ciência, decretado pelas Nações Unidas, e que se celebrará a 11 de fevereiro. Como nos anos anteriores, o objetivo deste evento é celebrar os feitos das Mulheres na Ciência e inspirar as gerações mais jovens a seguir carreiras na ciência. Mulheres e homens de todos os tipos de organizações científicas ir-se-ão reunir para partilhar o café da manhã, seja virtual ou pessoalmente. Um objetivo central também é estabelecer uma rede ativa entre homens e mulheres para superar as barreiras à igualdade de género na ciência.
O GWB facilita a formação de comunidades a uma escala local, regional e internacional para efetivamente partilhar ideias e estratégias para o progresso. Em Portugal, as mulheres químicas associam-se ao GWB desde a primeira edição, envolvendo cada vez mais instituições e ações diversas, colocando o nosso país no mapa do evento. A submissão de propostas de organização é efetuada diretamente no site da IUPAC em iupac.org/gwb/registration e o programa é divulgado por todo o Mundo.

Mais informações em iupac.org/gwb

\title{
PANACEA-Pan-European Solid-State NMR Infrastructure for Chemistry-Enabling Access
}

O Laboratório de Ressonância Magnética Nuclear (RMN) de Sólidos do CICECO e da Universidade de Aveiro integra um consórcio europeu financiado pela Comissão Europeia que liga em rede sete centros europeus e um americano congéneres e duas empresas, intitulado "PANACEA-Pan-European Solid-State NMR Infrastructure for Chemistry-Enabling Access". A investigação em RMN de sólidos tem três décadas de história em Aveiro e a integração nesta rede europeia confirma a excelência e a visibilidade internacional do laboratório do CICECO-UA. Neste projeto participam os membros do Departamento de Química João Rocha, Luís Mafra e Mariana Sardo.

A Rede PANACEA permitirá o acesso transnacional de estudantes, investigadores e técnicos da academia e das empresas às melhores infraestruturas europeias de RMN de sólidos, estimulando a colaboração entre os laboratórios que a integram, e promovendo a geração de novo conhecimento. As candidaturas podem ser submetidas a um painel de peritos a qualquer altura e, ao serem aprovadas, incluem as despesas de deslocação e alojamento do candidato, bem como os custos de utilização dos equipamentos. Toda a comunidade de Químicos está convidada a submeter propostas que considerem relevantes no âmbito dos seus tópicos de investigação, nos quais a RMN de estado sólido possa dar o seu contributo.

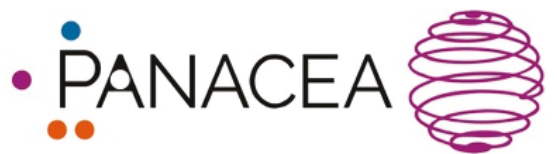

A Pan-European Solid-State NMR Infrastructure for Chemistry-Enabling Access

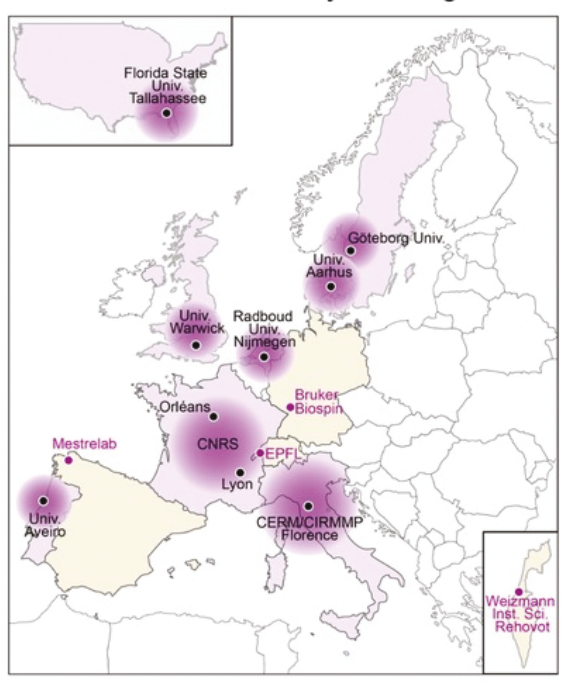

Para mais informações contactar Mariana

Sardo - CICECO/Universidade de Aveiro (msardo@ua.pt). 